\title{
LAGRANGE AND MOZART AS CRITICS OF DESCARTES
}

\author{
I. Grattan-Guinness \\ (Middlesex University at Enfield)
}

This article traces three lines of positive and negative inlluence which emanated from Descantes's Discours sur la méthode (1637), or at least were closely linked to it. Three areas of concern are involved: the relationship between geometry and algebra, celestial mechanics, and physiological psyclology. The two critics of the tille were contemporaries; reasons for their surprising conjunction will emerge at the end.

\section{Descartes on geometry and astronomy}

Descartes's Géometrie, published in 1637 (his 42nd year) as a supplentent to the Discours, meant what it said in the title. Although it is best remembered as a major source for the infiltration of algebra into geometry as analytic geometry, the work was basically geometrical in conception, with algebra serving as handmaiden. For example, means for judging the iniplicilly of curves were based upon traditional geometrical criteria, not on shortness of algebraic expressions. He also offered a proto-calculus method to determine the nomal to a curve from a double-root condition on a polynomial equation.

Scraps of Descartes's vorticial theory of planetary motion were presented in the Discours, but his main source was Le monde (1629-1637). In his Principia philosophicae (164t) he outlined some of his principles: that the planets were swept around their paths by a family of concentric rotating vortices; and that God would not permit clinos, so that a major issue was to determine equilibrium, with the planets reaching (somehow) their appropriate vortices. His theory was developed further, including quantitatively, by G.IV. Leibniz (1646-1716), whose ideas about the transition from one vortex to another one helped to launched energy mechanics via the notion of vis vira.

However, Descartes's mechanics were a major target of Isaac Newvton (1643-1727); even the title of his book Philosophiae naturalis principia mathematica (1687) seems to be a retort, perhaps at its largely qualitative nature. He gave strong arguments against the existence of vortices, and argued for a quite different mechanical system based upon central forces between particles and laws of reaction and of acceleration. He also developed a version of the full calculus, involving the determination of derivative and integral fimctions from a given function, not mere double root conditions to determine the tangent or nomal. I use the names from Leibniz's theory, for they have become standard: he developed it in the 1670s, about a decade after Newton and quite independently, and it involved quite diflerent concepts. Both theories, especially Leibniz's, gave a much more place to algebra than Descartes had granted.

\section{Descartes on 'the passions of the soul'}

The Principia philosophicae was dedicated to Princess Elizabeth of Bolemin; soon aflenvards Descartes wrote at her request on Les passions de liame. He also sent drafts of this work to another scholarly royal lady, Queen Cliristina of Sweden (1626-1689), with whom he had already corresponded about aspects of the Principia philosophicae. Les passions appeared in 1649, and was his last publication because he moved that September to Stockloolm to serve as court philosopher to Queen Clıristina: the conditions of employ'ment required him to rise in the 
early mornings of a Swedish winter to provide tutelage at 5 of the clock, with the result that he rapidly died, in February 1650.

Much of the content of Les passions was already in the Discours, but the presentation of them was more explicit and systematic. The book was an exercice in Descartes's penchant for classification and also a vehicle for his physiological reductionism. For him the soul fulfilled two roles: action or desires, and passions. The latter were transmitted by heat of the blood lying and moving as 'spirits' in the crevices of the brain. The conduit was the pineal gland, apparently chosen for its place as a single object in the human frame where so many other parts, such as the brain itself, came in twos.

Descartes classified the passions as follows. Six were primitive: love, hatred, desire. joy and sadness; and also admiration, which had a more rational disposition than the others and so was not accompanied by any changes in the heart or to the blood. From this sextet 34 more 'particular' passions were formed, as compounds: for example, gratitude, indignation and gaiety. The total number of passions was $40: 1$ do not regard as a coincidence that this devout Catholic decided upon this important Christian number for his aggregate.

\section{Queen Christina and the Accalemia degli Arcalia}

Four years after Descartes's death, Queen Christina converted to the Catholic faitl; according to her later testimony, he had been an important influence. This action caused her rapid abdication, whereupon she repaired for much of the rest of her life to Rome, the Catholic centre. There she founded an Academy in her garden (presumed shades of Plato) where literati and intellectuals sought for 'better morals', with Les passions as a guiding text.

The year after her death in 1689, an Accademia degli Arcadia was founded in Rome to pursue these ideals more formally; they remembered ler at an annual celebration. The pott Giovanni Crescimbeni (1663-1728) was the secretary from the founding until his death. Although the members - about 600 men by 1700 , and not only in Rome- were drawn from the upper classes, they feigned democracy by wearing the same apparel, that of shepherds which inspired the name of their organisation. One of their concerns was a desire to bring more order and probity to the preparation of libreati for operas, then still a rather new ant form. Composers early in association included Alessandro Scarlatti (1660-1725), who had conducted Queen Christina's orchestra at her private theatre from 1684. Their attention, however, focused on the texts, and their leading protégé came to exercise an extraordinary influence.

\section{The training and career of a Cartesian librettist}

Another founder of the Accademia was the lawyer Giovanni Gravina (1664-1712), although a split in 1711 caused him to found another academy named after himself. He had as cousin a minor philosopher and poet, Gregorio Caloprese (1650-1714/15), founded a philosophical school in Calabria in Southern Italy, where the instruction was based upon Les passions. In 1712 he introduced Caloprese in 1712 to a most promising youth, Pietro Trapassi (1698-1782), who studied under lyim for a few months. After moving back to Rome, Trapassi fell under the control of Gravina, who llellenised his name to 'Metastasio' and left him a considerable fortune alter dying in 1718. The young man squandered his money, but he absorbed further livavy doses of Les passions and began to orient his life towards literary' work, especially libretti.

Metastasio's training from Caloprese and Gravina and their Arcadian colleagues made him a Cartesian aesthete, giving him (supposedly) reasoned principles which he applied throughout his career, much of which was spent in Vienna as court poet. His librett, written in 
Italian, were normally based upon classical or mythological characters. Using stories with happy endings, he showed how reason could triumph over catastrophe, even over personal desires. He expressed an ideal which Crescimbeni had called 'mixed beauty': the internal mode which induced in a character love of virtue for general happiness, and the external mode which related to his social situation. His libretti were enormously influential, not only for their number (28) but especially for the fact that several of them were used dozens of times (sometimes in adaptations by others). The greatest composers of the day drew upon them: Handel, Gluck (see the next section), Scarlatti and Pergolesi, whose l'Olimpiade (1735) was one of the early classics, J.C. Bach and Cherubini. On occasion a composer set the same libretto more than once. Curiously and wastefully, ever since libretti have normally been used once only,

A major feature of Metastasian aesthetics was the assumption strongly implicit in Les passions and presumably based upon Descartes's reductionism, especially that the individnal (and thus a character) can experience only one passion at a sime. Thus operas written to libretti of this kind (not only by Metastasio) became known as 'opera seria', with passions experienced serially (although at that time the name 'dramma per musica' was more common). Tlie structure of the text was rigid; often 3 acts each with 12 scenes. Most arias were solos, although duets between leading characters were permitted. Arias followed a da capo form, although the soloist might be given some freedom to ornament in the reprise. The passion was statically conveyed throughout an aria, which might be written in a specifically associated key (for example. bravery in D, rage in d, yearning in $G$, and love in A). Often the character(s) exited on completion of the aria, taking his passion with him; then the next one would be exhibited in the aria following, perhaps with a transition convey'ed in intervening recitatives.

\section{Opera seria and its critics}

The main principles of opera seria were in place by the 1730 s, with works such as to a Metastasian libretto as early classics. But one result of the obviously false psychology which Descartes had proposed was that these operas were static and boring, and presented unbelievable characters in impossible situations. Efforts to approach reality came from the 1750s, partly influenced by the contemporary tradition of lighter and more realistic opera buffa. Two composers stand out.

Jean Philippe Rameau (1683-1764) came late in life to opera but then wrote a century of them, all tragedies. He brought harmonies and even modulations into recitatives, together with changes of metre and syncopation; he also used music of the opera in its overture. His approach was extended and even eclipsed by Christoph Willibald Gluck (1714-1787), who modified not only opera seria but also the French tradition of tragedie lyrique in three "reform operas' written in the last decade of his life. He brought back dance, and flight and machines, which the Accademia degli Arcadia had banned long before, extended the second section of a da capo aria and did not always use that structure, converted recitatives into ariosi, gave a much greater role to the chorus, and made his characters much more human-like. He did not use Metastasian libretti here; for example, Iphigenie en Tauride (1779) was based upon Racine. However, the revolution was conservative; several features of opera seria were still in place, such as the use of classical stories and passions in series.

Still more radical changes soon came, under the foree of the Enlightenment; and the most noteworthy composer was Wolfgang Amadeus Mozart (1756-1791) with his principal librettist Lorenzo da Ponte (1749-1838). In the three operas upon which they collaborated, La nozze de Figaro (1786), Don Giovami (1787) and Cosi fan tutti (1790), Cartesian principles were expli- 
citly rejected. Characters were real people, even identifiable ones, at least by type; passions were at work simultaneously in opera parallela (not a name of that time, but one that could have been coined). The texts contain complicated ensembles with overlapping conversations or switches from to another in rapid tandem; and within some aria or duets moods or feelings may modify. Correspondingly, the musical language was far more elaborate and contrapuntal.

Opera seria was not dead: Mozart himself produced two fine ones, of which the second, La clemenza di Tito (1791) to a Metastasian libretto modified into a more human form by da Ponte's student Caterino Mazzola (1745-1806), went back before Rameau in its musical style. But it was written to order; specifically, for the coronation of the new Holy Roman Emperur in Prague. In general the tradition was becoming steadily more passé; Mazzola's adaptation of Tito was the 40th use of Metastasio's libretto, but there were only three later ones, up to I803. Indeed, all of his libretti were largely ignored in the new century. Opera became secular, and static seriality was replaced by the dynamic parallelism of (fairly) real life.

\section{The stability problem in astronomy}

Exactly the same change took place in an important aspect of celestial mechanics. One belief common to Newton and Descartes was the central place of God, although again there were differences. Catholic Descartes put fonvard a cosmogony where God perfectly created the world but thereafter let it run on its own (a view which distressed some fellow believers). By contrast, Newton, a heretical Arian, was much concerned with the issue that the planetary system was rendered stable by God's will. His theory of central forces allowed the possibility that the cumulative effect of inter-planetary perturbing forces might drive a planet off the convex bounded orbit around the Sun; however, this would never happen, for God would alway's arrive in time and restore order.

A similar position on stability was maintained by another Catholic, Leonhard Eufer (1707-1783), the next great figure in Newtonian celestial mechanics. One of his major innovations, made in the late 1740 s, was to bring in a uniform method of handling perturbing forces by using expansions of the distance functions in trigonometric series. Unintentionally, it inspired from J. L. Lagrange (1736-1813) in 1774 a manner of secularising the stability problem: that is, to prove stability from the laws of Newtonian mechanics together with the assumption that the planets orbited around the Sun in the same direction. (Incidentally, here Newtonian mechanics was inferior to the vorticists, who explained co-orbitation in terms of the action of the same vortex family.) Transforming the independent variables, he converted the expansions into a sequence of anti-symmetric equations, and so brilliantly reduced the problem to an analysis of the reality of the latent roots of a certain type of matrix (to use the more modern language of the spectral theory of matrices which this very work helped to create). His conditions for stability were necessary but not sufficient; extending them was to be a great problem in both mathematics and celestial mechanics for over a century, and under its influence the theological approach to stability disappeared.

Lagrange presented his theory in a definitive form in his treatise Mechanique analitique (1788). The second word of his title, overused in mathematics, need explaining, referred to his attempt to algebraise mechanics: that is, to express all of its and theorems (such as stability) by means of general formulae without any recourse to geometric reasoning. Thus Descartes's view of the relationship between these two branches of mathematics was reversed.

However, as with opera seria, negative reactions came in abundance, especially in the new century. Geometrical thinking in mechanics retained much attraction, especially for its 
unmatchable facility in aiding the creation of new theories; in addition, Lagrange's view that dynamics was reducible to statics was ignored or even replaced by a greater emplasis on dynamics (the naturally wider range of phenomena, in any case), with a rise of energy mechanics which Leibniz had envisioned.

The bad news was not over. From 1772 Lagrange had attempted the same kind of reduction of the calculus, taking the Taylor expansion of a mathematical function as a basic principle and producing all required theorems and result by algebraic operations alone. But his approach lacked credibility; indeed, his basic principle was slrown by counter-example to be false. However Descartes was not vindicated; for a most influential theory was developed from the 1820s by Augustin-Louis Cauchy (1789-1857), based upon neither geometry nor algebra but upon the theory of limits which Newton had handled, although in an unrigorous way.

\section{Parallel processes}

Why combine music with mechanics when the two disciplines exercised no influence, positive or negative, upon each other? The reason lies in considerations of Zeitgeist, hopefully without the determinism that so often mars its use. Like a new Renaissance, part of the Enliglitenment credo was to reduce the pressure of Christianity upon cultural thinking and encourage the idea than mankind can do things: express conflicts among people rather than ponder the ordered sequence of passions from antiquity, and to prove the ordered sequence of orbital paths rather than invoke Divine intervention. The individual was seen as an active agent in intellectual and artistic life. Thus we see also, among many examples. Romanticism coming into both the arts and the sciences; appraisal of the regularities of life and the world by probability theory ratler than yes-no certainties; and above all, the philosophy of Immanuel Kant (1724-1804), based on the principle that we impose our ideas upon the world rather than the then normal vice versa.

Both Lagrange and Mozart lived through the new trends and reacted positively to them. Lagrange was classified as an atheist, although 'agnostic' would probably be a more accurate description (interestingly, that word was not created then). Mozart did not allow his $\mathrm{Ca}$ tholicism to accept all the social barriers; after all, Figaro wins over the Count.

\section{Bibliographical notes}

A good introduction to Descartes's Géométrie is provided in H.J.M. Bos, The representation of curves in Descartes's Geometrie', Archive for history of exact sciences, 24 (1981). 295-338. E. J. Aiton, The vortex theory of planetary motions (1972. London, Macdonald; and New York, American Elsevier) is a major source on this tradition in celestial mechanics. For the general progress of astronomy, still valuable is R. Grant, listory of physical astronomy, from the earliest ages to the middle of the nineteenth century (1852. London, Boh; repr. 1966. New York. Johnson). On the stability problem, an old source is complemented by a modern one: A. Gautier, Essai historique sur le problème des trois corps (1817, Paris, Courcier); and C.A. Wilson, 'Perturbation and solar tables from Lacaille to Delambre', drchive for history of exact sciences, 22 (1980), 53-188, 189-304.

On the various traditions of the mechanics and the calculus around 1800 , see respectively I. Grattan-Guinness, 'The varieties of meclanics by 1800', Historia mathematica, 17 (1990), 313-338; and his (ed.) From the calculus to set theory 1630-1910: an introductory history (1980. London, Duckworth), clis. 2 and 3 (with Descartes's method summarised in cl. 1). Lagrange`s personal and family background are very well documented in M.T. Borgato and 
L. Pepe, 'Sulle lettere familiari di Giuseppe Luigi Lagrange', Bollettino di storia delle scienze matematiche, 9 (1981), 193-318.

Among the various editions of Les passions, the one published in 1968 by Gallimard of Paris contains a long though rather over-written introduction by the editor, J.-M. Monnoyer. On Descartes's last employer, see F. W. Bain, Christina, Queen of Sweden (1890, London, IV.H. Allen). The Accademia was well recorded by Crescimbeni in his Storia dell'Accademia degli Arcadia instituta a Roma d'anno 1690 per la collivazione della scienza delle lettere e clella poesia (1804, London, Becket). More modern treatments include M. T. Acquaro Graziosi, L'Arcadia. Trecento anni di storia (1991, Rome, Polombi), light but with good illustrations. The role of Caloprese comes through in C. Compagnino and others (eds.), I/ setfecento: L'Arcadia a l'età delle reforme, vol. 6, tome 1 (1973, Rome and Bari, Laterza), esp. pp. 73-75, 270-273; also included on pp. 265-314 is a good survey by G. Nicastro of Metastasio, on whom the literaure is vast. W. Birini, L'Arcadia e il Metastasio (1968. Florence, La Nuova Italia) is more of a (good) literary than an historical examination.

For the tradition of opera seria and its musical and historical context, an excellent star can be made from various articles on opera and on the figures mentioned in the text in The new Grove dictionary of music and musicians (20 vols., 1980), and especially The new Grove dictionary of opera (4 vols., 1992) both edited by S. Sadie (London, MacMillan). In particular, the article on Metastasio by D. Neville in the latter work is an extraordinary source of information in its eleven pages. Handel was perhaps the greatest composer of opera seria, but apparently the Cartesian elements were not noted in England as they were on the Continent; I rely here, but nervously, on the silence over Descartes in IV. Dean, Handel and the opera seria (1970, London, OUP).

Da Ponte may well be a key figure in the change of stance over libretti; unfortunately his Memoirs (trans. E Abbott and A. Livingston: 1929, New York, Lippincott) are alınost deliberately uninformative, and of the various biographies the only one worth reading (H. Goertz, Mozarts Dichter Lorenzo de Ponte. Genie und Abenteuer (1985, Vienna, Österreichischer Bundesverlag)) is not too enlightening on this point. But Mozart's own conscious role in the changes is finely captured in the path-breaking study by N. Till, Mozart and the Enlightenment (1992, London, Faber and Faber). 